\title{
Co-Registration of Optically Sensed Images and Correlation (COSI-Corr): an Operational Methodology for Ground Deformation Measurements
}

\author{
Sébastien Leprince*, François Ayoub*, Yann Klinger ${ }^{\dagger}$ and Jean-Philippe Avouac* \\ * California Institute of Technology, Pasadena, CA 91125, USA \\ Email: leprincs@caltech.edu \\ $\dagger$ Institut de Physique du Globe de Paris, 75005 Paris, France
}

\begin{abstract}
Recent methodological progress, Co-Registration of Optically Sensed Images and Correlation, outlined here, makes it possible to measure horizontal ground deformation from optical images on an operational basis, using the COSI-Corr software package. In particular, its sub-pixel capabilities allow for accurate mapping of surface ruptures and measurement of co-seismic offsets. We retrieved the fault rupture of the $2005 \mathrm{Mw} 7.6$ Kashmir earthquake from ASTER images, and we also present a dense mapping of the $1992 \mathrm{Mw} 7.3$ Landers earthquake of California, from the mosaicking of 30 pairs of aerial images.
\end{abstract}

\section{INTRODUCTION}

In addition to seismological records, the knowledge of ruptured fault geometry and co-seismic ground deformations are key data to investigate the mechanics of seismic rupture. In principle, this information can be retrieved from sub-pixel correlation of pre- and post-earthquake remotely sensed optical images [1], as illustrated by earlier promising results [2], [3], [4]. However, this technique suffers from numerous limitations, mostly due to uncertainties on the imaging systems and on the platform attitudes. These uncertainties lead to unmodelled distortions and stereoscopic effects that are biasing the ground deformation measurements.

In this paper, we take advantage of a newly available technique that allows for precise correction of most of these limitations, and for accurate estimation of sub-pixel displacement between images [5]. This new technique, Co-Registration of Optically Sensed Images and Correlation (COSI-Corr), has been implemented in a software package and is freely available from the Caltech Tectonics Observatory web site ${ }^{1}$. Our goal is to show its ability to measure horizontal co-seismic ground deformations. In particular, to complement the studies in [5] and [6], we investigate the use of ASTER (Advanced Spaceborne Thermal Emission and Reflection Radiometer) satellite and aerial images.

We first review the key steps that define the COSI-Corr methodology. Secondly, in complement to [7], we study two ASTER images bracketing the 2005, Mw 7.6 Kashmir earthquake. Thirdly, in complement to [6] and [8], using 30 pairs

\footnotetext{
${ }^{1}$ URL: http://www.tectonics.caltech.edu/slip_history/spot_coseis/
}

of aerial photographs, we measure the horizontal co-seismic ground displacement induced by the 1992, Mw 7.3 Landers earthquake of California. Finally, we open the discussion on new applications.

\section{COSI-CORR Methodology}

COSI-Corr proposes a methodology that allows for an automatic and precise ortho-rectification and co-registration of satellite or aerial images [5]. The procedure does not require external information such as GPS measurements of ground control points (GCPs), and is solely based on the knowledge of the topography and on the ancillary data provided with the observing platform (positions, velocities, attitudes variations and pointing directions for spacecrafts, or calibration reports for aerial photographs.) Sub-pixel change detection is then applied on the set of ortho-images produced.

The precise ortho-rectification procedure relies on the automatic generation of precise GCPs, which are generated such that the correction they imply on the viewing geometry of the observing platform allows for precise ortho-rectification and co-registration of the images. To make this process automatic and as bias-free as possible, the GCPs generation and the viewing geometry parameters are jointly optimized: we generate a precise set of GCPs from a raw image (slave), with respect to an already ortho-rectified image (master), by iteratively refining a rough selection of GCPs. Initial GCPs are derived from tie points roughly selected between the orthorectified master and the raw slave images. Image patches from the raw slave image are ortho-rectified and their misregistration with the master ortho-image are estimated from correlation. A precise set of GCPs is produced when the misregistration measured at each patch converges to a minimum. The GCPs generation is made independent of any external data by using a shaded image of the digital elevation model (DEM) as the first ortho-rectified master, and the first ortho-rectified image produced then becomes the master for subsequent slave images. This approach is applicable worldwide taking advantage of the availability of accurate DEMs with global coverage (e.g., Shuttle Radar Topography Mission - SRTM.) 
Once a set of precise GCPs has been produced, we compute the inverse mapping matrices that associate ground coordinates with raw pixel coordinates. They define an irregular resampling grid in the raw image. To avoid the introduction of aliasing in the ortho-rectified image, the irregular resampling problem is accounted for and the ortho-image is then built [5].

Horizontal ground displacements are retrieved from the subpixel correlation of the pre- and post-earthquake ortho-rectified images. Image correlation is achieved with an iterative, unbiased processor that estimates the phase plane in the Fourier domain [5]. This process leads to two correlation images, each representing one of the horizontal ground displacement component (East-West and North-South).

This methodology applies to any imaging system. Here, we apply it to pushbroom satellite images (ASTER), and to aerial images. In pushbroom imaging systems, all optical parts remain fixed during the acquisition, and the scanning is accomplished by the forward motion of the spacecraft. Each line in the image depends on the varying attitudes of the platform. In this case, COSI-Corr corrects the viewing parameters by linearly correcting the camera look directions to compensate for attitude drifts and sensor orientation uncertainties during image acquisition. In contrast, aerial photographs are images acquired from only one exposure. The geometric bias induced by the acquisition system is stationary and is compensated for using the traditional photogrammetric equations [6].

Raw images are wrapped onto the topography within the DEM resolution, and pairwise co-registered with a $\frac{1}{50}$ pixel accuracy, allowing for the measurement of horizontal fault offset with an accuracy on the order of $\frac{1}{20}$ of the pixel size [5].

\section{THE 2005, Mw 7.6 KASHMIR EARTHQUAKE FROM ASTER IMAGES}

We report on the rupture of the Oct. 8 2005, Mw 7.6 Kashmir earthquake from $15 \mathrm{~m}$ ASTER images acquired on Nov. 14, 2000 and on Oct. 27, 2005. A $30 \mathrm{~m}$ DEM produced from these ASTER images was used. Fig. 1 shows the North-South component of the ground offsets measured from correlation of the ortho-rectified and co-registered ASTER VNIR 3N images. This first analysis readily shows that the rupture reached the surface, although field evidence for fault ruptures was scant, and it provides a $70 \mathrm{~km}$ mapping of the fault geometry with an accuracy not achievable from field measurements. In addition to the co-seismic signal, a wave pattern, running in the satellite along-track direction, reflects the undersampling of the satellite attitudes that therefore could not be accurately accounted for during ortho-rectification (we see here a pattern characteristic of unrecorded pitch variations, a similar pattern on the EastWest component reflected roll variations.) This pattern was removed from subtraction, in the across-track direction, of several profiles running in the along-track direction and not intersecting with the tectonic signal. This yields Fig. 2.

Fig. 2 allows us to quantify the horizontal co-seismic ground displacement. The horizontal slip vector on the fault could be measured accurately from profiles running across the fault trace, including the fault-perpendicular component

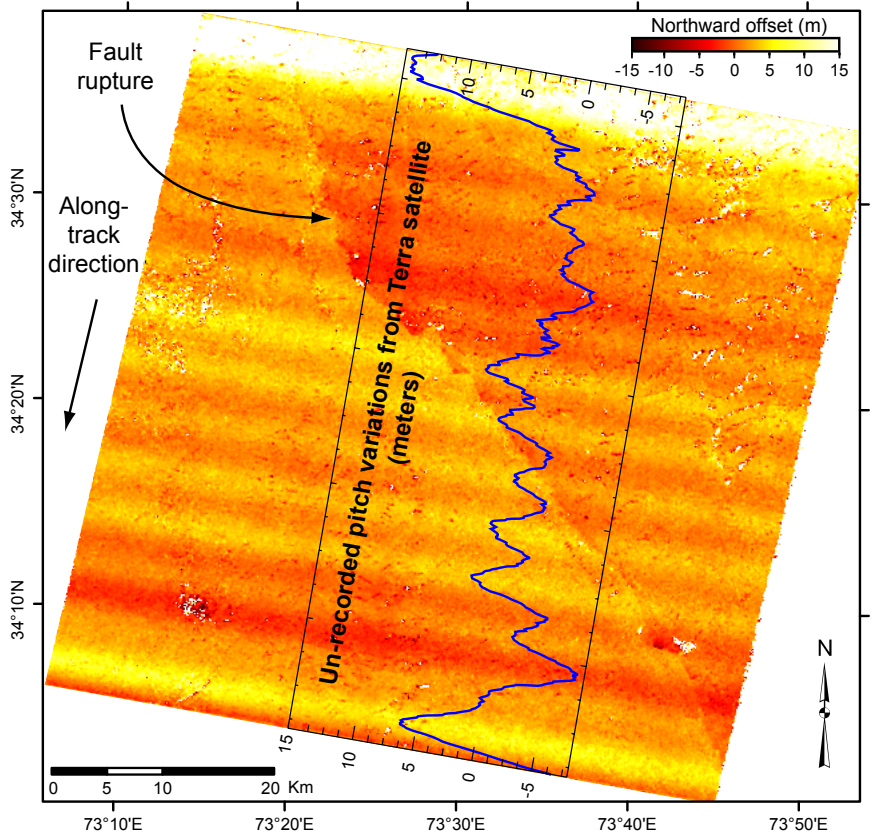

Fig. 1: Northward component of the co-seismic offset field from the 2005 Kashmir earthquake seen from ASTER images (positive to the North.) This correlation image was obtained with a sliding $32 \times 32$ pixels correlation window and 8 pixels step, leading to a ground resolution of $120 \mathrm{~m}$. No measurement is assigned to white points, where correlation was lost. Correlation was lost mainly due to landslides or variation of the snow cover. The fault rupture is visible as a discontinuity in the offset field. A wave pattern, attributed to pitch variations, is biasing quantitative measurements.

of horizontal displacements that could not be measured in the field [7]. Surface displacements indicate nearly pure thrusting with an average slip of about $5 \mathrm{~m}$, peaking at $7 \mathrm{~m}$.

\section{The 1992, Mw 7.3 LANDERS EARTHQUAKE FROM AERIAL PHOTOGRAPHS}

Using aerial and satellite imagery, we studied the Mw 7.3 1992 Landers, California earthquake, which produced a $75 \mathrm{~km}$ surface rupture with an average right-lateral slip of $3 \mathrm{~m}$. From the USGS-NAPP (U.S. Geological Survey - National Aerial Photography Program), 60 digitized photographs taken in 1989 and 1995 and covering the rupture were paired. Those images, announced at $1 \mathrm{~m}$ resolution, each have a footprint of slightly less than $10 \times 10 \mathrm{~km}$. In addition, a $5 \mathrm{~m}$ ground resolution 2002 SPOT 5 image and a displacement field of the area obtained from SPOT imagery, [2], were available. The $10 \mathrm{~m}$ NED DEM was used to account for the topography.

The SPOT 5 image, previously co-registered to the DEM and ortho-rectified on a $5 \mathrm{~m}$ resolution grid, was used as a common reference to register and ortho-rectify the aerial images from 1995, as they were both post-earthquake. Between 5 to 10 GCPs per image were selected and optimized with the SPOT 5 image [5], [6]. Optimizations were processed 


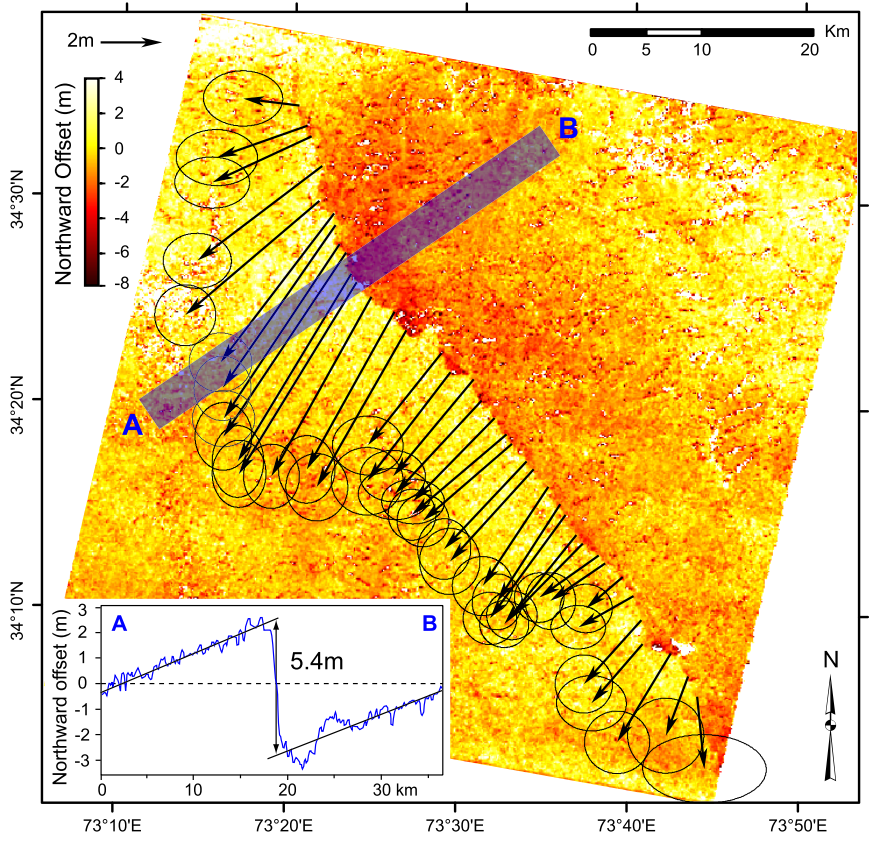

Fig. 2: Northward component of the co-seismic offset field from the 2005 Kashmir earthquake seen from ASTER images (positive to the North). Attitude variations were subtracted from Fig. 1. Arrows represent the horizontal surface fault slip. They are determined from linear least square adjustment, on each side of the fault and on each NS and EW images, of stacked profiles running perpendicularly to the rupture. Profiles are stacked over a width of $6 \mathrm{~km}$ and a length of $18 \mathrm{~km}$. Ellipses show the $95 \%$ confidence intervals. A longer profile highlights this procedure.

independently, although an improved method would jointly optimize the GCPs of all 1995 images using a bundle block adjustment. Images from 1995 were then ortho-rectified on a $1 \mathrm{~m}$ resolution grid.

Tie points were selected between the 1995 ortho-rectified images and their corresponding images from 1989. However, in order to correctly co-register the images, ground displacement at the resulting GCPs locations had to be accounted for. Indeed, these GCPs, necessarily located in the near fault zone area due to the small footprint of aerial images, sustained some ground deformation. The possible ground displacement at the locations of the GCPs would then be incorrectly compensated if we did not account for it during the optimization. As seen in [6], this compensation would corrupt the deformation signal on long wavelengths, but would not affect the localization and slip of the fault. Nevertheless, the displacement map obtained from SPOT imagery was used as an estimate of the ground displacement at GCPs location.

GCPs from images of 1989 were optimized with their corresponding 1995 images as reference. At this stage, the use of a bundle block adjustment for the 1989 images would be difficult as the best possible co-registration was needed between each image pair. Using a block bundle adjustment would minimize the global error over all pairs but would introduce local mis-registration that would be perceived as ground displacement. Pairs of orthorectified images were then correlated using a sliding $64 \times 64 \mathrm{~m}$ window.

A mosaic of the correlations is presented in Fig. 3. Most of the entire surface rupture was mapped, revealing small fault branches that were hardly recognized in the field.

\section{CONCLUSION}

We successfully applied the COSI-Corr methodology, newly developed, and processed two independent ASTER images, as well as 30 overlapping aerial image pairs. We precisely retrieved the horizontal co-seismic displacement fields induced by the recent 2005 Kashmir earthquake, and by the 1992 Landers earthquake from USGS aerial archives.

COSI-Corr proves to be robust and offers an operational methodology to the measurement of horizontal ground deformations. In the case of earthquake studies, the possibility of accurately recovering the fault normal component, and the fact that the technique allows us to measure distributed deformation off the main fault trace, are of particular interest. The subpixel capability makes this technique suitable for many types of sensors and many other applications can be foreseen. The estimation of glacier flow velocities or sand dunes migration rates are being investigated.

\section{ACKNOWLEDGMENT}

The authors would like to thank the Observatoire de Paris for providing us with outstanding digitization of the aerial films, and Pablo Musé for his useful comments.

\section{REFERENCES}

[1] R. Crippen and R. Blom, "Measurement of subresolution terrain displacements using Spot panchromatic imagery," in Proc. IEEE Int. Geosci. and Remote Sens. Symp., vol. 3, June 1991, pp. 1667-1670.

[2] N. Van Puymbroeck, R. Michel, R. Binet, J.-P. Avouac, and J. Taboury, "Measuring earthquakes from optical satellite images," Appl. Opt., vol. 39, no. 20, pp. 3486-3494, 2000.

[3] S. Dominguez, J.-P. Avouac, and R. Michel, "Horizontal coseismic deformation of the 1999 Chi-Chi earthquake measured from SPOT satellite images; implications for the seismic cycle along the western foothills of central Taiwan," J. Geophys. Res., vol. 108, no. B2, 2003.

[4] Y. Klinger, R. Michel, and R. King, "Evidence for a barrier model from Mw7.8 kokoxili (Tibet) earthquake slip-distribution," Earth Planet. Sci. Lett., vol. 242, pp. 354-364, 2006.

[5] S. Leprince, S. Barbot, F. Ayoub, and J. P. Avouac, "Automatic and precise ortho-rectification, co-registration and sub-pixel correlation of satellite images, application to ground deformation measurements," IEEE Trans. Geosci. Remote Sens., to appear June 2007.

[6] F. Ayoub, S. Leprince, and J. P. Avouac, "Measuring co-seismic ground deformation from aerial photography using cosi-corr," Remote Sensing Environ., submitted 2007.

[7] J. P. Avouac, F. Ayoub, S. Leprince, O. Konca, and D. Helmberger, "The 2005, Mw 7.6 Kashmir earthquake, rupture kinematics from sub-pixel correlation of ASTER images and seismic waveforms analysis," Earth Planet. Sci. Lett., vol. 249, no. 3-4, pp. 514-528, 2006.

[8] R. Michel and J. P. Avouac, "Coseismic surface deformation from air photos: The Kickapoo step over in the 1992 Landers rupture," J. Geophys. Res., vol. 111, no. B03408, 2006.

[9] K. Sieh, L. Jones, E. Hauksson, K. Hudnut, D. Eberhart-Phillips, T. Heaton, S. Hough, K. Hutton, H. Kanamori, A. Lilje, S. Lindvall, S. McGill, J. Mori, C. Rubin, J. A. Spotila, J. Stock, H. Thio, J. Treiman, B. Wernicke, and J. Zachariasen, "Near-field investigations of the landers earthquake sequence, april to july, 1992," Science, vol. 260, pp. 171-176, 1993. 


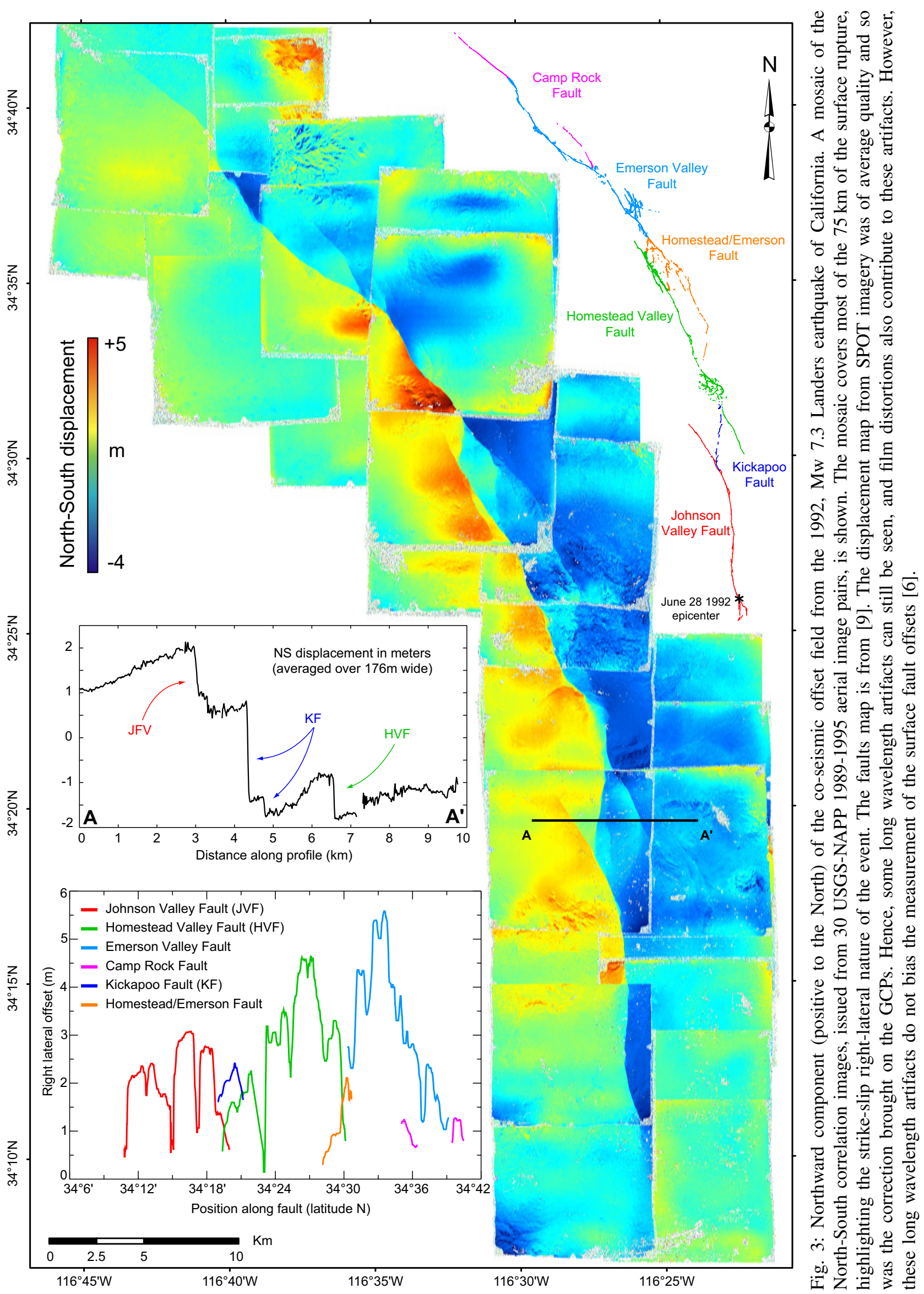

